\title{
A Cost and Performance Comparison of Packed Bed and Structured Thermocline Thermal Energy Storage Systems
}

\author{
Matthew N. Strasser and R. Paneer Selvam* \\ Department of Civil Engineering, University of Arkansas, Fayetteville, AR 72701, USA \\ * Author to whom correspondence should be addressed, E-Mail: rps@uark.edu
}

\begin{abstract}
A structured concrete thermocline thermal energy storage (TES) system is proposed as an alternative to currently-used TES systems. The issues of material settlement and thermal ratcheting found in packed bed thermocline TES systems is avoided by replacing the packed aggregate bed with structured high-temperature concrete. A summary of all utility scale TES systems with integrated TES in existence today is provided and discussed. Cost reduction options such as replacing two-tank systems with single-tank systems and replacing liquid storage media with solid storage media are discussed along with limitations of both options. Numeric models are developed to simulate the performance of utility scale packed bed and structured thermocline TES systems; efficiencies of $92.37 \%$ and $84 \%$ are modeled for packed-bed and structured systems. A complete cost analysis of utility-scale, 2,165 MWh packed bed and structured systems is conducted; capacity costs of $\$ 30 / \mathrm{kWh}$ and $\$ 34 / \mathrm{kWh}$ are determined for packed bed and structured systems respectively. A structured concrete thermocline is deemed to be a viable TES option due to its low cost and the fact that there are no concerns of thermal ratcheting of the tank.
\end{abstract}

Keywords: Solar energy, thermal energy storage, thermocline, molten salt, cost analysis Nomenclature

$\alpha \quad$ Thermal diffusivity $\left(\mathrm{m}^{2} / \mathrm{s}\right)$

Bi Biot number, $\mathrm{hL}_{\mathrm{c}} / \mathrm{k}(\mathrm{dim})$

$\mathrm{c}_{\mathrm{p}} \quad$ Specific heat at constant pressure $\left(\mathrm{J} / \mathrm{kg} .{ }^{\circ} \mathrm{C}\right)$

d Bed particle diameter $(\mathrm{m})$

$\mathrm{D}_{\mathrm{y}} \quad$ Node spacing in PBTC model (m)

$\mathrm{D}_{\mathrm{h}} \quad$ Hydraulic diameter $(\mathrm{m})$ 
$\varepsilon \quad$ Porosity (dim)

h Convection coefficient $\left(\mathrm{W} / \mathrm{m}^{2} \cdot{ }^{\circ} \mathrm{C}\right)$

$\mathrm{h}_{\mathrm{v}} \quad$ Volumetric convection coefficient $\left(\mathrm{W} / \mathrm{m}^{3} \cdot{ }^{\circ} \mathrm{C}\right)$

k Thermal conductivity $\left(\mathrm{W} / \mathrm{m} .{ }^{\circ} \mathrm{C}\right)$

$\mathrm{k}_{1}, \mathrm{k}_{2}$ Empirical coefficients associated with the Ergun equation (dim)

L Length of concrete plate or packed bed (m)

$\mathrm{L}_{\mathrm{c}} \quad$ Characteristic length, $\mathrm{d} / 6$ for sphere (m)

$\dot{\mathrm{m}} \quad$ Fluid mass flow rate $(\mathrm{kg} / \mathrm{s})$

$\rho \quad$ Density $\left(\mathrm{kg} / \mathrm{m}^{3}\right)$

P Wetted perimeter $(\mathrm{m})$

$\Delta \mathrm{P} \quad$ Pressure drop $(\mathrm{Pa})$

$\mathrm{R}_{\mathrm{i}} \quad$ Inner radius (half of fluid channel thickness) (m)

$\mathrm{R}_{\mathrm{o}} \quad$ Outer radius (half of fluid channel thickness plus axisymmetric element wall thickness) (m)

S Cross-sectional area of fluid flow channel $\left(\mathrm{m}^{2}\right)$

$\mathrm{t} \quad$ time $(\mathrm{s})$

T Temperature $\left({ }^{\circ} \mathrm{C}\right)$

$\mathrm{T}_{\mathrm{i}} \quad$ Thickness of fluid flow channel (m)

$\mathrm{T}_{\mathrm{o}} \quad$ Thickness of fluid flow channel plus thickness of concrete plate (m)

v Kinematic viscosity $\left(\mathrm{m}^{2} / \mathrm{s}\right)$

V Bulk fluid velocity $(\mathrm{m} / \mathrm{s})$

$\Phi \quad$ Empirical coefficient associated with the Ergun equation (dim)

\section{Subscripts}

F Fluid 
M Material

\author{
Acronyms \\ CSP Concentrating Solar Power \\ DTC Direct Thermocline \\ HTF Heat Transfer Fluid \\ PBTC Packed-Bed Thermocline \\ PV Photovoltaic \\ SCTC Structured-Concrete Thermocline \\ TES Thermal Energy Storage \\ TTI Two-Tank Indirect
}

\title{
I. Introduction
}

Increasing global energy demands and diminishing fossil fuel resources have raised interest in renewable energy resources. Sufficient solar irradiance is incident on the Earth's surface to fuel the production of electrical energy for all of its inhabitants [1]. However, efficient and reliable methods of harvesting solar energy for power production are needed. Solar energy is harvested and converted to electrical energy using one of two technologies: photovoltaic (PV) panels or concentrating solar power (CSP) plants.

PV panels convert solar energy to electric energy directly; this method of conversion is mature, scalable, and relatively low cost: $\$ 4,740 / \mathrm{kW}$ for utility installments (>100kW) [2]. Two primary drawbacks are associated with PV: electric power output is subject to rapid fluctuations and is only available when the sun is shining. Considering the first drawback, power production can rapidly shift from peak to minimal and back to peak as clouds drift in front of the sun. It is challenging and costly to design control systems and backup generators capable of responding to these fluctuations rapidly enough to maintain a steady supply of power to the grid [3]. Considering the second drawback, since PV panels convert solar energy directly to electrical energy, it follows that electricity can only be produced when the sun is shining. Unfortunately, 
times of peak power demand (shortly after sunset) do not coincide with periods of peak irradiance; though excess electrical energy can be produced during the day and utilized during evening hours, the high cost of large-scale electrical energy storage is not viable (Table 1).

Though CSP is a younger and more costly conversion technology, approximately $\$ 5,500 / \mathrm{kW}$ for utility installments ( $>50 \mathrm{~kW}$ ) [2], it is a more viable option than PV at the utility scale because CSP plants can be easily integrated with thermal energy storage (TES). Excess solar energy can be collected and stored as thermal energy. This energy can then be dispatched at will for conversion to electrical energy in a traditional Rankine steam power cycle. This effective "thermal battery" allows the plant to continue power production well into the hours of peak demand after sunset.

Table 1: Energy Storage Concepts and Costs [4-6]

\begin{tabular}{|c|c|c|}
\hline $\begin{array}{c}\text { Energy Storage } \\
\text { Concept }\end{array}$ & $\begin{array}{c}\text { Capacity Cost } \\
(\$ / \mathbf{k W h})\end{array}$ & $\begin{array}{c}\text { Efficiency } \\
(\%)\end{array}$ \\
\hline Sealed Lead Acid Battery & $\$ 333.00$ & $80.00 \%$ \\
\hline Lithium Ion Battery & $\$ 600.00$ & $85.00 \%$ \\
\hline Super Capacitor & $\$ 10,000.00$ & $95.00 \%$ \\
\hline High Speed Flywheel & $\$ 1,600.00$ & $95.00 \%$ \\
\hline Pumped Hydro & $\$ 75.00$ & $85.00 \%$ \\
\hline Two-Tank Indirect & $\$ 89.00$ & $97.00 \%$ \\
\hline Two-Tank Direct & $\$ 50.00$ & $97.00 \%$ \\
\hline Packed-Bed Thermocline & $\$ 34.00$ & $93.00 \%$ \\
\hline
\end{tabular}

Table 2: Existing CSP Plants with Integrated TES [7]

\begin{tabular}{|c|c|c|c|c|c|c|c|}
\hline \multicolumn{8}{|c|}{ CURRENTLY IN OPERATION } \\
\hline $\begin{array}{l}\text { Plant } \\
\text { Title }\end{array}$ & $\begin{array}{c}\text { Capacity } \\
\left(\mathbf{M W}_{\mathrm{e}}\right)\end{array}$ & $\begin{array}{c}\text { Concentrator } \\
\text { Type }\end{array}$ & $\begin{array}{c}\text { Storage } \\
\text { Media }\end{array}$ & $\begin{array}{l}\text { Low } \\
\left({ }^{\circ} \mathrm{C}\right)\end{array}$ & $\begin{array}{l}\text { High } \\
\left({ }^{\circ} \mathrm{C}\right)\end{array}$ & $\begin{array}{c}\text { Hours of } \\
\text { TES Backup }\end{array}$ & $\begin{array}{c}\text { TES } \\
\text { Configuration }\end{array}$ \\
\hline Andasol 1-2-3 & 150 & Parabolic Trough & Nitrate Salt & 290 & 390 & 7.5 & 2-Tank, Indirect \\
\hline Archimede & 5 & Parabolic Trough & Nitrate Salt & 290 & 550 & 8 & 2-Tank, Direct \\
\hline Arcosol 50 & 50 & Parabolic Trough & Nitrate Salt & 290 & 390 & 8 & 2-Tank, Indirect \\
\hline Aste $1 a-1 b$ & 100 & Parabolic Trough & Nitrate Salt & 290 & 390 & 8 & 2-Tank, Indirect \\
\hline Astexol II & 50 & Parabolic Trough & Nitrate Salt & 290 & 390 & 8 & 2-Tank, Indirect \\
\hline Extresol 1-2-3 & 150 & Parabolic Trough & Nitrate Salt & 290 & 390 & 8 & 2-Tank, Indirect \\
\hline Gemasolar & 19.9 & Central Receiver & Nitrate Salt & 290 & 565 & 15 & 2-Tank, Direct \\
\hline La Africana & 50 & Parabolic Trough & Nitrate Salt & 290 & 390 & 7.5 & 2-Tank, Indirect \\
\hline La Dehesa & 50 & Parabolic Trough & Nitrate Salt & 298 & 390 & 7.5 & 2-Tank, Indirect \\
\hline La Florida & 50 & Parabolic Trough & Nitrate Salt & 298 & 390 & 7.5 & 2-Tank, Indirect \\
\hline Manchasol 1-2 & 100 & Parabolic Trough & Nitrate Salt & 293 & 390 & 7.5 & 2-Tank, Indirect \\
\hline PS 10 & 11 & Central Receiver & water & \multicolumn{2}{|c|}{$<300$} & 1 & Steam, Direct \\
\hline PS 20 & 20 & Central Receiver & water & \multicolumn{2}{|c|}{$<300$} & 1 & Steam, Direct \\
\hline Solana & 250 & Parabolic Trough & Nitrate Salt & 290 & 373 & 6 & 2-Tank,Indirec \\
\hline Termesol 50 & 50 & Parabolic Trough & Nitrate Salt & 293 & 390 & 7.5 & 2-Tank, Indirect \\
\hline Termesol 1-2 & 100 & Parabolic Trough & Nitrate Salt & 293 & 393 & 9 & 2-Tank, Indirect \\
\hline \multicolumn{8}{|c|}{ UNDER CONSTRUCTION } \\
\hline Airlight Baha & 3 & arabolic Trough & Air/Gravel & 250 & 650 & 12 & 1-Tank \\
\hline
\end{tabular}




\begin{tabular}{lcllcccc} 
Arenales & 50 & Parabolic Trough & Nitrate Salt & 293 & 393 & 7 & 2-Tank, Indirect \\
Bokpoort & 50 & Parabolic Trough & Nitrate Salt & 293 & 393 & 9 & 2-Tank, Indirect \\
Caceres & 50 & Parabolic Trough & Nitrate Salt & 293 & 393 & 7.5 & 2-Tank, Indirect \\
Casablanca & 50 & Parabolic Trough & Nitrate Salt & 293 & 393 & 7.5 & 2-Tank, Indirect \\
Crescent Dundes & 110 & Central Receiver & Nitrate Salt & 290 & 565 & 10 & 2-Tank, Direct \\
Diwakar & 100 & Parabolic Trough & Nitrate Salt & N/A & N/A & 4 & 2-Tank, Indirect \\
Gujarat Soalar One & 25 & Parabolic Trough & Nitrate Salt & 293 & 393 & 9 & 2-Tank, Indirect \\
KaXu Solar One & 100 & Parabolic Trough & Nitrate Salt & N/A & N/A & 3 & 2-Tank, Indirect \\
Khi Solar One & 50 & Central Receiver & water & N/A & N/A & 2 & Steam, Direct \\
KVK Solar Project & 100 & Parabolic Trough & Nitrate Salt & N/A & N/A & 4 & 2-Tank, Indirect \\
Noor I & 150 & Parabolic Trough & Nitrate Salt & 293 & 393 & 3 & 2-Tank, Indirect \\
\hline
\end{tabular}

A summary of all CSP plants with integrated TES that are in operation or are under construction is provided in Table 2 [7]. From this list, it can be seen that the current standard in TES is the two-tank indirect (TTI) configuration with nitrate salt as the energy storage media, and the operating temperature range of $290^{\circ} \mathrm{C}-390^{\circ} \mathrm{C}$. Figure $1 \mathrm{~A}$ illustrates the TTI TES system configuration and a parabolic trough solar collector field. Solar energy is collected in the solar field, where parabolic troughs focus irradiance on receivers, through which thermal oil heat transfer fluid (HTF) is circulated. The oil is then circulated to an oil-to-salt heat exchanger, where the collected energy is transferred to nitrate salt. Heated salt is stored in a "hot" tank until the energy is dispatched, at which point the oil and salt are circulated through a salt-to-oil heat exchange. The hot oil then circulates to the power block and the "cold" salt is stored in the "cold" tank until it is re-heated.

Salt is utilized as energy storage media primarily because it is much more cost-effective than using thermal oil as storage media. To put this in perspective, the thermal mass of solar salt $\left(\rho \cdot c_{p}\right)$ of solar salt and Therminol VP-1 (thermal oil) are relatively comparable at 2.485 $\mathrm{MW} / \mathrm{m}^{3} \cdot{ }^{\circ} \mathrm{C}$ and $1.865 \mathrm{MW} / \mathrm{m}^{3}{ }^{\circ} \mathrm{C}$ [9]. However, the difference in operating temperature differentials of the two fluids is significant, at $275^{\circ} \mathrm{C}$ and $100^{\circ} \mathrm{C}$ respectively. This means that on a volumetric basis, solar salt has 3.664 times the energy storage density of thermal oil. The consequence of this increased volume is that more storage media and larger storage systems are needed corresponding higher system costs. Therefore, although salts are corrosive and challenging to work with, the cost reduction benefit outweighs the associated complications.

Referencing Table 1, it can be seen that the TTI configuration is considerably more costly than the other TES configurations (last two entries in Table 1). Therefore, it is logical that one would question why a more expensive technology is still the standard. Referencing Table 2, it can be seen that the majority of CSP facilities utilize parabolic troughs to collect solar energy; 
these systems have a lower concentration ratio than tower-type systems, meaning that the operating temperature is lower. Utilizing the TTI configuration means that oil is circulated through the solar receiver instead of salt, thereby eliminating concerns of HTF solidification in the collector (solidification of salt occurs at approximately $222^{\circ} \mathrm{C}$ ). Furthermore, the TTI configuration affords the near-perfect efficiency of $97 \%$ and a constant discharge fluid temperature [6].

The primary drawback associated with the TTI configuration is its high cost. Several of the primary cost-inflating factors are as follow: steel tanks, large oil and salt inventories, and oilto-salt heat exchangers. The two storage tanks of a TTI system are constructed from stainless steel to avoid being corroded by the nitrate salt storage media, therefore, they are very costly. Though nitrate salts are chemically stable in the presence of air up to $565^{\circ} \mathrm{C}$, the energy storage temperature is limited by the chemical stability of thermal oils (around $400^{\circ} \mathrm{C}$ ) to peak operating temperature of $390^{\circ} \mathrm{C}$. Therefore, a much larger nitrate salt inventory is required than would be necessary if the salt's heat capacity was fully utilized.

An alternative to the TTI configuration that takes full advantage of the salt's storage capacity is the two-tank direct (TTD) configuration. In the TTD configuration, the thermal oil and oil-to-salt heat exchanger are eliminated, and the salt is circulated directly to the collector field to be heated before entering storage. Additionally, the TTD system affords high efficiency of $97 \%$ similar to that of the TTI system. Although the TTD configuration provides storage at lower cost to than the TTI configuration, the presence of two large storage tanks and a large salt inventory still leaves the system cost relatively high.

A cost-reducing alternative configuration to the TTD system is the direct thermocline (DTC) configuration, a schematic of which is provided in Figure 1B. In a thermocline type configuration, hot and cold media are stored in the same tank, thereby eliminating one of the costly storage tanks required by the TTI configuration. Nitrate salt, serving the dual function of HTF and storage media, is heated directly in the solar receiver then circulated to storage, thereby eliminating the costly oil inventory and oil-to-salt heat exchangers. Finally, the energy storage temperature is no longer limited by the oil's chemical stability, therefore the energy storage temperature can be increased from the limit of $390^{\circ} \mathrm{C}$ to $565^{\circ} \mathrm{C}$. Consequentially, the required quantity of nitrate salt is reduced. Further reduction of the nitrate salt inventory can be achieved by filling a significant volume of the thermocline tank with a "packed bed" of low-cost solid 

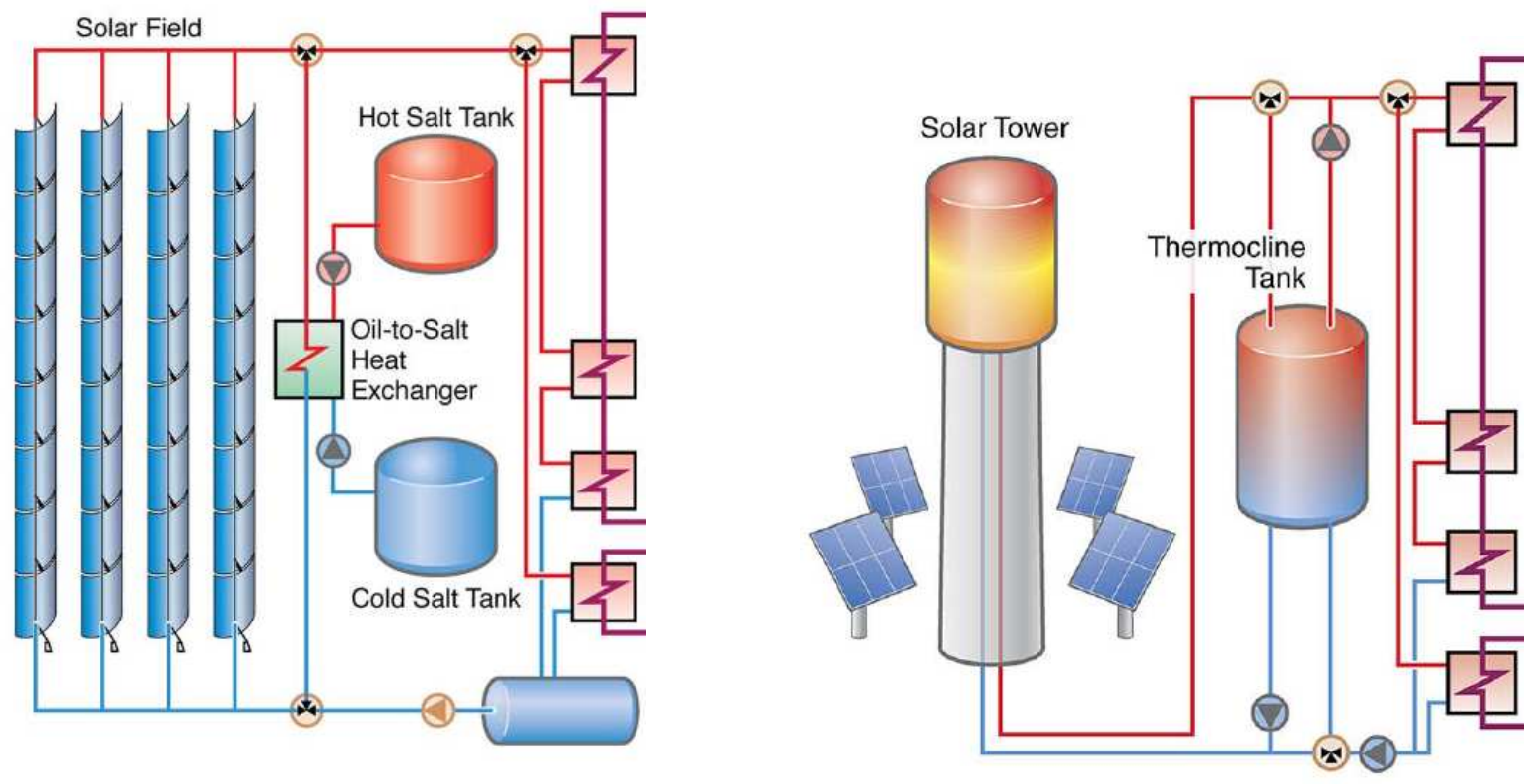

Figure 1: Parabolic trough receivers with indirect TES system (Left, A) and central receiver with direct TES system (Right, B) [5]

Though the DTC configuration offers TES at a lower cost than the TTI configuration, two primary concerns prevent its large-scale incorporation. The first concern is shared for all direct TES systems incorporating nitrate salt as storage media: solidification of nitrate salt in the solar collection field. The solution to this problem is relatively simple, as heaters can be incorporated to prevent the salt temperature from falling below a set temperature $\left(300^{\circ} \mathrm{C}\right)$ for a direct two-tank configuration or by adding heat traces to the piping for DTC configurations.

The second and primary concern for DTC TES systems is thermal ratcheting of the tank's walls. To date, the solid media tested and used in thermocline TES systems is a "packed-bed" of aggregate or aggregate and sand [8,11-12]. During the charging phase, hot salt is added to the top of the tank; the tank is made from stainless steel which has a considerably higher thermal strain rate than does the aggregate composing the bed. As the tank's walls heat and expand, aggregate settles to occupy this new volume. During discharging, cold salt is added to the base of the tank; consequently, the tank's walls cool and contract. However, the settled aggregate 
prevents the walls from returning to their initial position, resulting in the introduction of residual stresses to the tank walls. Cyclic charge and discharge processes can lead to catastrophic rupture of the tank [13]. A recent study investigates thermal ratcheting in the thermocline storage tank at the Solar One facility (operated from 1982-1986), comparing results from a finite element model to data from strain gauges on the tank [14]. A relatively small operating temperature range is considered: $204^{\circ} \mathrm{C}-304^{\circ} \mathrm{C}$; the model accurately predicts stress in the tank walls to be $190 \mathrm{MPa}$, less than half of the reported yield strength for the steel tank walls, $400 \mathrm{MPa}$. However, as energy storage temperature ranges increase, such as the $300^{\circ} \mathrm{C}-585^{\circ} \mathrm{C}$ range considered in this work, the difference in thermal strain (which is directly proportional to temperature) between the stainless steel tank and aggregate bed becomes more significant. This leads to an accelerated and more severe level of thermal ratcheting.

Three approaches have been proposed to mitigate thermal ratcheting: utilizing a "corrugated liner" [13], utilizing a novel tank design that encourages the aggregate to expand vertically [15], and replacing the packed aggregate bed with structured concrete filler [16]. Though the first concept is innovative, the author does not clearly explain how the liner will resist the cyclic stresses of the ratcheting without being damaged. Furthermore, the author does not propose a material from which the liner could be made. The second concept, while also innovative, is developed for an air-packed bed thermocline, and the bed walls are constructed from concrete. Testing reported by Skinner [17] finds that even very dense concrete is permeated by molten salt; therefore it is likely that a concrete containment tank is not viable for a thermocline utilizing salt as liquid media. Construction of a large-scale steel tank having the novel frustum configuration would likely be quite costly due to the engineering and custom fabrication required. The third approach is very straightforward: structured high-temperature concrete replaces the packed aggregate bed, thereby eliminating concerns of thermal ratcheting altogether.

Structured concreted has been proposed as a low-cost energy storage media, reportedly providing sensible heat storage at costs as low as $\$ 1 / \mathrm{kWh}_{\mathrm{t}}$ [12]. TES systems employing concrete as storage media typically consist of concrete prisms with embedded heat exchangers; a HTF is circulated through the heat exchanger to transfer energy to and from the system. The DLR research center reports much work on this concept, utilizing both modeling and large-scale test modules [18-21]. Energy is stored up to the temperature limit of $400^{\circ} \mathrm{C}$ in large-scale test 
modules and concrete is developed that is compatible with energy storage up to the temperature limit of $500^{\circ} \mathrm{C}$. Work performed at the University of Arkansas reports energy storage tests utilizing prisms composed of high-performance concrete cast around stainless steel heat exchangers up to the temperature limit of $450^{\circ} \mathrm{C}$ with nitrate salt as $\mathrm{HTF}$ [22]. Also reported is the development of concrete compatible with energy storage up to the temperature limit of $600^{\circ} \mathrm{C}$ [23]. Although the cost of the high-performance concrete is low, Skinner et al. [22] conclude that the concrete modules are not a cost-effective system configuration due to the high cost of the stainless steel heat exchangers required.

It is proposed that the packed aggregate bed typically used in the thermocline TES concept be replaced with the low-cost, high-performance concrete reported in Skinner et al. [22] (See Figures 3-5). In this work, numeric models are presented and utilized to compare the performance of PBTC and structured concrete thermocline (SCTC) TES systems. The systems considered are utility-scale, having 2,165 MWh storage capacity. Subsequently, cost analysis of the two systems is performed using the model laid out by EPRI [5], and the unit capacity cost (cost per unit energy storage) of both systems is given. Finally, conclusions are drawn regarding the viability of a SCTC.

\section{Thermocline Models}

In this section, the numeric models developed to study both thermocline configurations are presented and discussed briefly. Both models are finite difference (FD) based heat transfer models, with the PBTC model being 1D and the SCTC models being 2D. Properties of the molten salt are provided in Table 3 for the lower, upper, and median temperatures considered in the modeling. In some of our previous work [24], comparisons of models utilizing constant and temperature-dependent fluid properties confirm that for a salt-based thermocline system, the assumption of constant fluid properties is reasonable. However, it is noted that if a fluid such as air is utilized, where thermal properties strongly depend on temperature, than the assumption of constant fluid properties would not be valid. The concrete utilized herein is proprietary and high strength. Neither the properties of the concrete nor the aggregate show significant temperature dependence, therefore, all material properties in the models are assumed constant. Computational domains are illustrated, governing equations are provided, and significant assumptions and 
boundary conditions for each model are discussed. Further detail and discussion of the models is available in the work of Brown et al. [16] and Strasser [24].

Table 3: Thermal properties of solar salt at minimum, median, and maximum temperature range considered in modeling [30].

\begin{tabular}{|c|c|c|c|c|}
\hline \multirow{2}{*}{ Property } & \multicolumn{3}{|c|}{$\mathbf{T}\left({ }^{\circ} \mathbf{C}\right)$} & \multirow{2}{*}{$\boldsymbol{\Delta}_{\mathbf{3 0 0}^{\circ}-585^{\circ}}$} \\
\cline { 2 - 4 } & $\mathbf{3 0 0}$ & $\mathbf{4 4 2 . 5}$ & $\mathbf{5 8 5}$ & \\
\hline $\boldsymbol{\rho}\left(\mathbf{k g} / \mathbf{m}^{\mathbf{3}}\right)$ & 1899.2 & 1818.57 & 1717.94 & $-9.54 \%$ \\
$\mathbf{c p}\left(\mathbf{J} / \mathbf{k g} .{ }^{\circ} \mathbf{C}\right)$ & 1391.4 & 1366.89 & 1342.38 & $-3.52 \%$ \\
$\mathbf{k}\left(\mathbf{W} / \mathbf{m} .{ }^{\circ} \mathbf{C}\right)$ & 0.5 & 0.527 & 0.554 & $10.80 \%$ \\
\hline
\end{tabular}

\section{PBTC Model}

The PBTC model employs the 1D Schumann [25] energy equations (1) and (2). Schumann's equations are widely accepted for modelling interstitial heat transfer for fluid flowing through a packed bed [26] and have successfully been validated through experimentation and comparison with the Solar One PBTC TES system [8,27-30]. Subscripts 'F' and 'B' correspond to fluid and bed respectively. Primary simplifying assumptions are bulleted below. The computation domain considered in formulating the PBTC model is illustrated in Figure 2. Note that the direction of fluid flow corresponds to charging.

- No radial temperature gradients or flow profiles exist within the bed (heat transfer is 1D).

- This assumption is reasonable, as uniform flow exists throughout the bed and the tank is assumed adiabatic.

- The particles composing the bed are small enough or have high enough thermal diffusivity such that it may be assumed that no thermal gradients exist within the particles (particles are lumped masses).

○ In the current work, $\mathrm{Bi}=0.33$, which does not satisfy the standard criterion $(\mathrm{Bi}<$ 0.1 ) for the assumption of lumped thermal mass.

- The high $\mathrm{Bi}$ number is accounted for through the definition of an "effective convection coefficient" which allows the particles in the packed bed to still be simulated via the lumped thermal mass assumption.

- Conductive heat transfer within the fluid or between the solid particles composing the bed is small relative to convective heat transfer and can be neglected (particles are in point contact). 
○ Numerical investigation in [31] shows that intraparticle conduction has negligible influence on the performance of a PBTC even for beds composed of particles having very high thermal conductivity.

The system is assumed to be well-insulated, therefore adiabatic on the sides and both ends. Furthermore, all solid and liquid media in the system is initially at the minimum temperature $\left(300^{\circ} \mathrm{C}\right)$. The volumetric heat transfer coefficient " $\mathrm{h}_{\mathrm{v}}$ " appearing in (2) is computed as suggested in $\mathrm{Xu}$ et al. [31]. During charging, the temperature at the top of the tank is specified to the maximum operating temperature $\left(585^{\circ} \mathrm{C}\right)$, simulating an inflow of heated fluid, and the solid and fluid temperature profiles within the tank are computed. During discharging, the temperature at the base of the tank is specified to the minimum operating temperature, simulating an inflow of cold fluid, and the solid and fluid temperature profiles within the tank are computed.

The convective heat transfer coefficient " $h$ " is computed as specified in [33] for flow over a sphere. The corresponding Biot number is 0.33 , which does not satisfy the typical criterion of $\mathrm{Bi}<0.1$ for the lumped thermal mass assumption. Therefore, "h" is reduced using the method of $\mathrm{Xu}$ et al. [34], equating to the so-defined "effective heat transfer coefficient ( $\left.\mathrm{h}_{\mathrm{eff}}\right)$ ". Finally, the effective volumetric heat transfer coefficient appearing in (2) is defined as " $\mathrm{h}_{\mathrm{v}}=$ $6 \mathrm{~h}_{\mathrm{eff}}(1-\varepsilon) / \mathrm{d} "[8]$.

(1) and (2) are discretized utilizing a first order upwinding scheme. An implicit solution is attained for the fluid-phase temperature profile utilizing a Gauss-Seidel solver; subsequently, the solid-phase temperature profile is solved for explicitly. This process is sub-iterated five times (found through convergence studies to be sufficient), to account for nonlinearity in the system of equations (1) and (2). The packed bed is discretized with 201 nodes along its height $(\Delta=0.07 \mathrm{~m})$ and the time step utilized is $5 \mathrm{~s}$ (both values selected from convergence studies). The resulting CFL $<1$ (mean fluid velocity of $0.0025 \mathrm{~m} / \mathrm{s}$ ) indicates that this combination of node spacing and time step are acceptable.

Although (1) and (2) are in their own right linear equations, nonlinearity emerges due to the implicit solution type of the system. This is because both the expression for the fluid phase and the solid phase contain the other term as an unknown. Therefore, when solving for the fluid temperature profile at the upcoming time step, it is initially assumed that the temperature distribution in the solid media will remain the same as the present temperature distribution in the upcoming time step. After solving the fluid temperature profile, for the upcoming time step, the 
temperature profile of the solid media is computed explicitly using the now-known fluid temperature profile at the upcoming time step. Sub-iteration of this process at each time step allows accurate solution of the two unknowns. An alternative approach would be to solve (1) and (2) using an explicit approach. However, the associated stability criterion reduces the minimum allowable time step significantly.

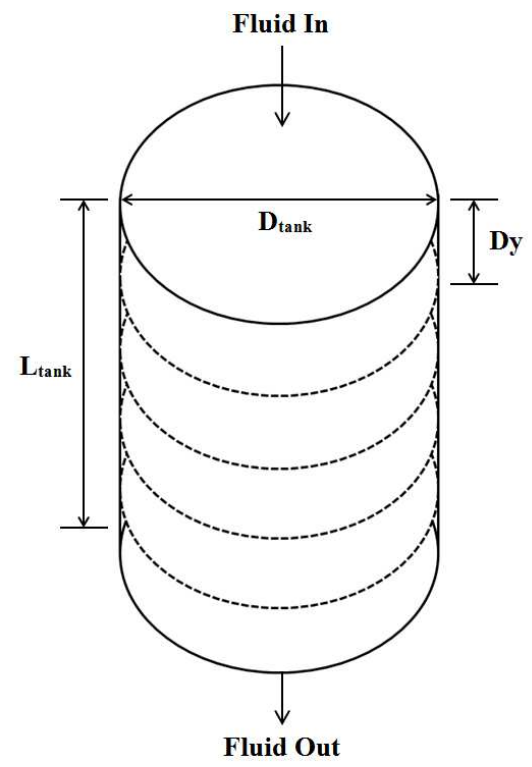

Figure 2: PBTC Model Computational Domain

$$
\begin{aligned}
& \left(\rho \mathrm{C}_{\mathrm{p}}\right)_{\mathrm{F}} \varepsilon \frac{\partial \mathrm{T}_{\mathrm{F}}}{\partial \mathrm{t}}=-\frac{\left(\dot{\mathrm{m}} \mathrm{C}_{\mathrm{p}}\right)_{\mathrm{F}}}{\mathrm{A}_{\mathrm{c}}} \frac{\partial \mathrm{T}_{\mathrm{F}}}{\partial_{\mathrm{y}}}-\mathrm{h}_{\mathrm{v}}\left(\mathrm{T}_{\mathrm{F}}-\mathrm{T}_{\mathrm{B}}\right) \\
& \left(\rho \mathrm{C}_{\mathrm{p}}\right)_{\mathrm{B}}(1-\varepsilon) \frac{\partial \mathrm{T}_{\mathrm{B}}}{\partial \mathrm{t}}=-\mathrm{h}_{\mathrm{v}}\left(\mathrm{T}_{\mathrm{B}}-\mathrm{T}_{\mathrm{F}}\right)
\end{aligned}
$$

\section{SCTC Model}

Two geometries of structured concrete elements are considered in this study: axisymmetric and parallel-plate. Figure 3 is an illustration of the cross section of a thermocline tank populated with concrete elements of each configuration as seen from above. It is assumed that uniform fluid flow is present throughout the tank, therefore, the thermal performance of a single concrete element is reflective of the performance of all of the elements in each respective system. Figure 4 and Figure 5 are illustrations of the axisymmetric and parallel plate models respectively. Due to thermal symmetry, only one-half the concrete element's thickness and onehalf of the flow channel $\left(T_{o}\right.$ and $\left.T_{i}\right)$ are considered for the parallel plate model, as indicated by the hatched region of Figure 5. Note that if either concrete geometry was implemented in a true 

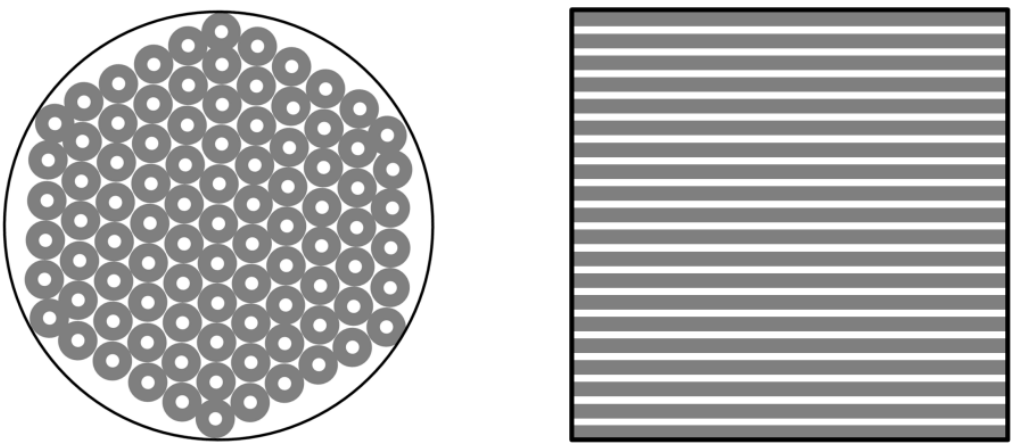

Figure 3: Cross-Sectional View of Thermocline Tank Populated with Concrete Elements having Axisymmetric (Left) and Parallel-Plate (Right) Concrete Configurations.
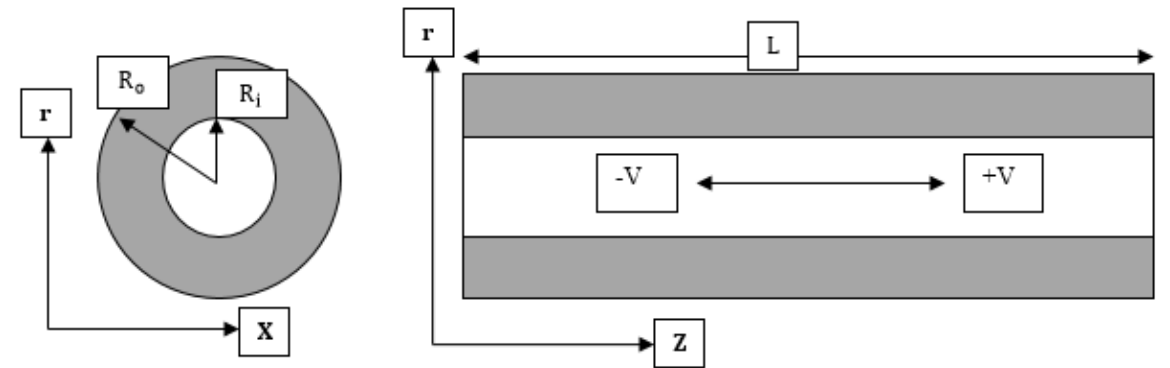

Figure 4: Cross-Sectional (Left) and Longitudinal (Right) Illustrations of an Axisymmetric Concrete Element.

system, gaps around the edges of the elements at the tank walls would have to be filled to force uniform flow through/between the elements. Namely, "S", the cross sectional area considered in (3) and (5) is constant for all elements in the tank. It is also likely that a square-shaped tank cross section would also be considered for the parallel-plate configuration so that only plates of a single size would need to be fabricated.

Although the cross section of the tank containing parallel plates of concrete would likely be square, the cost estimation procedures have only been developed for TES systems having cylindrical tanks [5]. It is beyond the scope of the current work to develop now cost estimation procedures considering a square-cross sectioned tank. As stated in the previous paragraph, it is assumed in the model that the same flow rate is present between all concrete elements. Therefore, the performance of the model is not dependent upon the assumed cross section of the tank. To avoid confusion, although the parallel-plate SCTC would likely have a square-shaped cross section, it shall be considered as a circular cross section in this work. 




Figure 5: Cross-Sectional (Left) and Longitudinal (Right) Illustrations of Two Parallel-Plate Concrete Elements. The hatched region represents the computational domain considered.

Governing equations for the two concrete element configurations are developed from the work of Schmidt \& Wilmot [32]. (3) and (4) correspond to the axisymmetric element configuration and (5) and (6) correspond to the parallel-plate configuration, with subscripts ' $F$ ' and ' $\mathrm{M}$ ' correspond to fluid and concrete respectively. Unlike the particles composing the packed bed in the PBTC model (particles are in point contact), the concrete elements are continuous, therefore conduction within the concrete elements is considered.

For axisymmetric model:

$$
\begin{aligned}
& \frac{\partial \mathrm{T}_{\mathrm{F}}}{\partial \mathrm{t}}+\mathrm{V} \frac{\partial \mathrm{T}_{\mathrm{F}}}{\partial \mathrm{z}}+\frac{\mathrm{hP}}{\mathrm{S}\left(\rho \mathrm{C}_{\mathrm{p}}\right)_{\mathrm{F}}}\left(\mathrm{T}_{\mathrm{F}}-\mathrm{T}_{\mathrm{M}}\right)=0 \\
& \frac{1}{\alpha_{\mathrm{M}}} \frac{\partial \mathrm{T}_{\mathrm{M}}}{\partial \mathrm{t}}=\frac{1}{\mathrm{r}} \frac{\partial}{\partial \mathrm{r}}\left(\mathrm{r} \frac{\partial \mathrm{T}_{\mathrm{M}}}{\partial \mathrm{r}}\right)+\frac{\partial^{2} \mathrm{~T}_{\mathrm{M}}}{\partial \mathrm{z}^{2}}
\end{aligned}
$$

For parallel plate model:

$$
\begin{aligned}
& \frac{\partial \mathrm{T}_{\mathrm{F}}}{\partial \mathrm{t}}+\mathrm{V} \frac{\partial \mathrm{T}_{\mathrm{F}}}{\partial \mathrm{z}}+\frac{\mathrm{hP}}{\mathrm{S}\left(\rho \mathrm{C}_{\mathrm{p}}\right)_{\mathrm{F}}}\left(\mathrm{T}_{\mathrm{F}}-\mathrm{T}_{\mathrm{M}}\right)=0 \\
& \frac{1}{\alpha_{\mathrm{M}}} \frac{\partial \mathrm{T}_{\mathrm{M}}}{\partial \mathrm{t}}=\frac{\partial^{2} \mathrm{~T}_{\mathrm{M}}}{\partial^{2} \mathrm{y}}+\frac{\partial^{2} \mathrm{~T}_{\mathrm{M}}}{\partial \mathrm{z}^{2}}
\end{aligned}
$$

Figure 6 is an illustration of the SCTC model's boundary conditions as applied to the computational domain of the parallel-plate concrete element configuration (hatched region of Figure 5). The SCTC is assumed to be well-insulated, therefore adiabatic on the sides and ends. A conduction-convection boundary condition is applied at the salt/concrete interface, as the rate 
of heat conduction from the concrete surface is equivalent to the rate of convection to the surface. The convection coefficient for either configuration is computed utilizing classical solutions for duct flow as defined by Çengel [33]. The concrete and salt temperatures are the same at the concrete/salt interface $\left(\mathrm{J}_{1}\right.$ in Figure 7$)$, and the temperature differential used in completing the convective heat transfer is that between $J_{1}$ and $J_{2}$. During charging, the fluid temperature at the top of the $\operatorname{tank}(\mathrm{z}=0)$ is set equal to the maximum operating temperature, and the solid and fluid temperature profiles along "z" are solved for. During discharging, the fluid temperature at the base of the $\operatorname{tank}(\mathrm{z}=\mathrm{L})$ is set equal to the minimum operating temperature, and the solid and fluid temperature profiles along " $\mathrm{z}$ " are solved for.

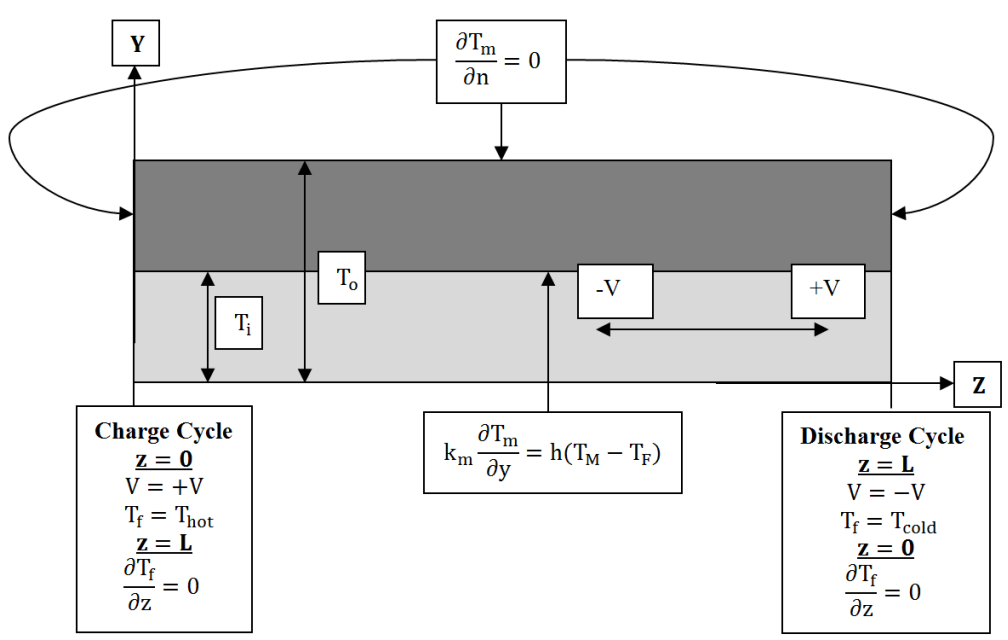

Figure 6: Illustration of Boundary Conditions Applied to Computational Domain (Hatched Region of Figure 3)

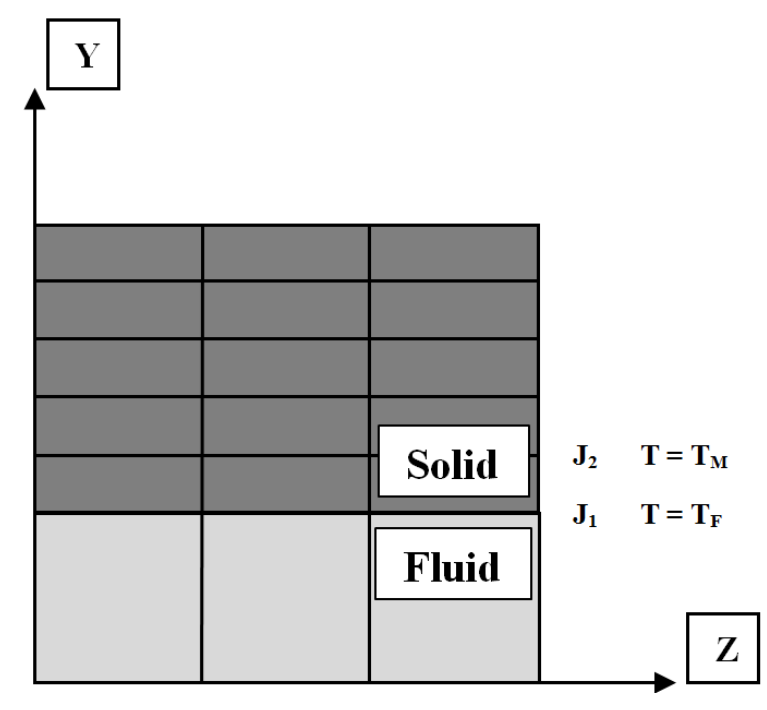


Figure 7: Illustration of nodes used in temperature differential of convection term of (3 or 5).

The SCTC model is discretized utilizing first order upwinding for the three first order partial derivatives in (3 and 4) and (5 and 6), for the axisymmetric and parallel-plate concrete element configurations respectively, and using second order central difference terms for the second order derivatives in (4) and (6). An implicit solution is attained for the fluid temperature profile using a Gauss-Seidel solver, then the solid temperature profile is solved for explicitly. This solution procedure is sub-iterated five times at each time step (yielding a converged solution), to reduce nonlinearity between the solid and fluid phases (See discussion on page 10). Following convergence studies, 101 nodes are considered along the length of the plate $(\Delta=0.14$ $\mathrm{m}$ ), and 51 nodes are considered across the thickness of the half-plate (Reference Figure 5, thermal symmetry allows consideration of only half the plate thickness). The time step considered is $10 \mathrm{~s}$ resulting in resulting $\mathrm{CFL}<1$, indicating this combination of node spacing and time step is acceptable.

\section{Performance of Thermocline Models}

A significant drawback associated with solid TES media is that the temperature of the fluid discharged from the storage system declines in the latter stages of the discharging process leading to decreased power block efficiency and wasted energy (Energy retrieved below the limiting minimum temperature) [20]. This decline in outlet temperature can be attributed to the development of thermal gradients within the solid media. Utilizing small solid elements reduces the magnitude of thermal gradients and exposes much material surface area for heat transfer, which is the reason PBTC's are very efficient. In preliminary analysis of the SCTC, this was not well-recognized, " $\mathrm{R}_{\mathrm{o}}-\mathrm{R}_{\mathrm{i}}$ " $=4 \mathrm{~cm}$ and " $\mathrm{T}_{\mathrm{o}}-\mathrm{T}_{\mathrm{i}}$ " $=7 \mathrm{~cm}$; consequently, low efficiencies of $62 \%$ and $65 \%$ are reported for SCTC systems utilizing the axisymmetric and parallel-plate concrete configurations respectively [16]. These low efficiencies can be understood through observation of the poor stratification seen in the concrete elements in the temperature profiles during the charge process as presented in Figure 8. 

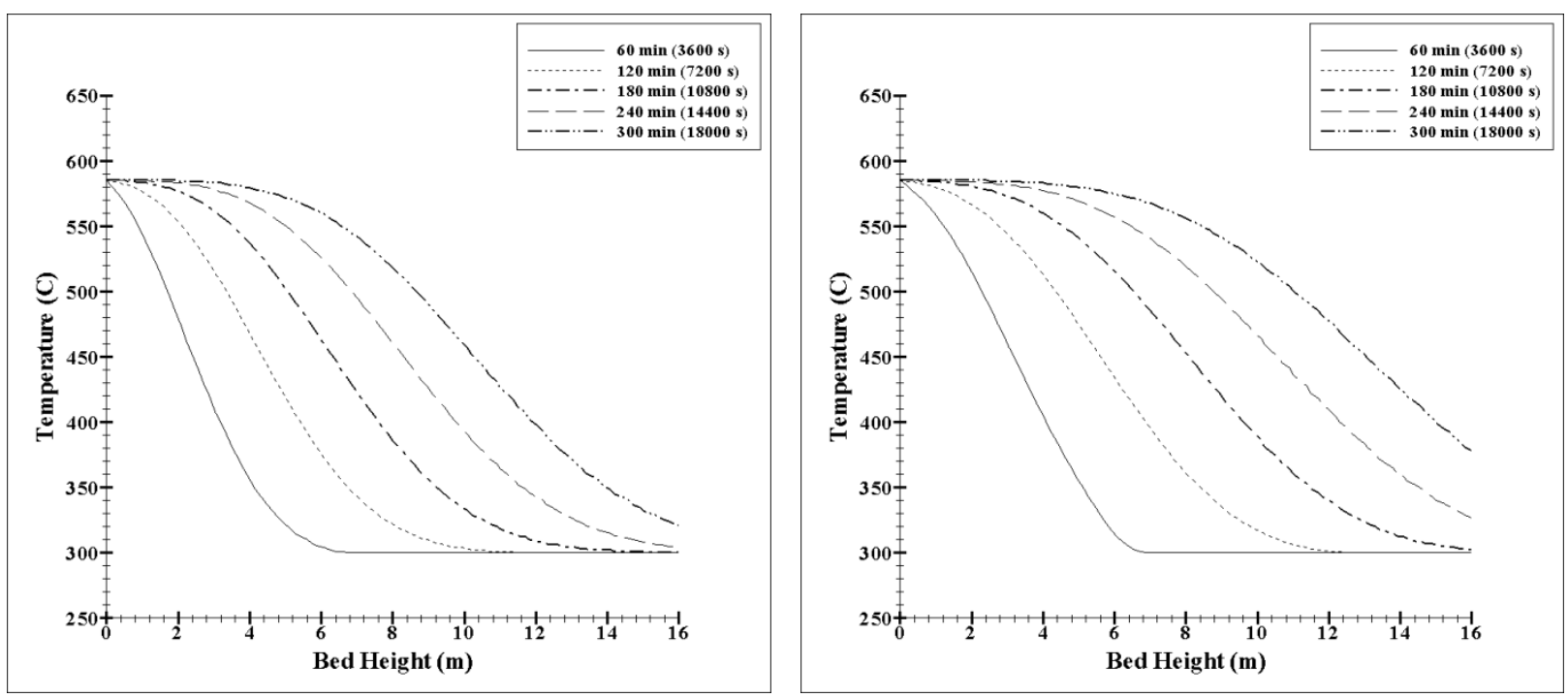

Figure 8: Solid media temperature profiles during the charging process for SCTC having Axisymmetric (Left) and Parallel-Plate (Right) Concrete Element Configurations.

Based upon the preliminary study, it is concluded that the axisymmetric configuration is less efficient than the parallel plate configuration. Furthermore, the axisymmetric configuration consumes more space than the parallel plate configuration (less concrete per unit floor space) and, axisymmetric elements are more difficult and expensive to construct than the slab-like plates. Therefore, only the parallel plate configuration is considered from this point forth.

In this comparison, limestone aggregate having average diameter of $1.9 \mathrm{~cm}$ is considered for the bed of the PBTC, and concrete plates having thickness of $2.2 \mathrm{~cm}$ and spacing of $1.1 \mathrm{~cm}$ are considered for the SCTC. This corresponds to both tank tanks being occupied with $67 \%$ solid and $33 \%$ liquid media respectively. This porosity is utilized, because experimental measurements reported in [15] for beds composed of rock of similar size $(2-3 \mathrm{~cm})$ approach porosity of 0.325 beyond the first meter of depth. Both beds have height of $14 \mathrm{~m}$, and diameters are $40 \mathrm{~m}$ and 42.5 $\mathrm{m}$ for the PBTC and SCTC respectively (both have the same storage capacity). The mass flow rate for the systems $(1861 \mathrm{~kg} / \mathrm{s}$ herein corresponding to velocities of $0.0025 \mathrm{~m} / \mathrm{s} \mathrm{\&} 0.0022 \mathrm{~m} / \mathrm{s}$ in the $40 \mathrm{~m} \& 42.5 \mathrm{~m}$ diameter tanks respectively) is set such that $13 \mathrm{~m}$ of the bed can be charged to $585^{\circ} \mathrm{C}$ if all heat input to the system is stored during the four-hour charging process. Finally, an operating temperature range of $300^{\circ} \mathrm{C}$ to $585^{\circ} \mathrm{C}$ is set for the solar salt heat transfer fluid. A summary of the average thermal properties of the TES media is provided in Table 4.

Table 4: Thermal properties of TES media. 
The pressure drop across the packed bed is computed utilizing (7), a version of Ergun's equation given by [15]. Empirical coefficients $\mathrm{k}_{1}=201, \mathrm{k}_{2}=1.83$, and $\Phi=0.6$ are from experimental curve fit of measured pressure loss for flow through beds of aggregate. Pressure drop across the $14 \mathrm{~m}$ bed is $1.52 \mathrm{kPa}$ meaning the work necessary to overcome this pressure drop is $1.56 \mathrm{~kW}$ (work required is the product of pressure drop and volumetric flow rate). The input work requirement to overcome the pressure drop is negligible compared to the output of the PBTC. The SCTC does not have obstructions within the solid media, meaning the pressure drop in this system will be less. Therefore, losses associated with pressure drop across the packed bed are not considered in computing the efficiency of the system.

$$
\frac{\Delta \mathrm{P}}{\mathrm{L}}=\mathrm{k}_{1} \frac{(1-\varepsilon)^{2}}{\Phi^{2} \varepsilon^{3}} \frac{\mu \mathrm{V}}{\mathrm{d}^{2}}+\mathrm{k}_{2} \frac{(1-\varepsilon)}{\Phi \varepsilon^{3}} \frac{\rho \mathrm{V}^{2}}{\mathrm{~d}}
$$

The efficiency of the systems is defined as the amount of usable energy retrieved from the system divided by the sum of the amount of energy input into the system and the energy not successfully stored during the charge process (fluid exiting the tank at greater than $300^{\circ} \mathrm{C}$ ). As energy is retrieved from storage, the temperature at which energy is retrieved from storage falls below a level at which power can be efficiently produced. In this work, the limiting temperature is $500^{\circ} \mathrm{C}$, and when the temperature of the discharge temperature of the fluid reaches this point, the discharge cycle ceases (the remaining energy in storage is considered lost). Modelled efficiencies for the PBTC and SCTC systems are $92.4 \%$ and $84 \%$ respectively.

Though the efficiency of each system is determined analytically, a qualitative analysis of the system's efficiency can be made by examining the shape of the temperature profile in the thermocline tank. It is desirable for the thermal gradient, thermocline region, to occupy a minimal region of the tank (ideally the temperature profile should be a step function); this signifies that there is excellent heat transfer between the solid and liquid media and minimal mixing of the hot and cold regions of the tank. To illustrate this point, consider the charge- 
process temperature profiles of the PBTC (Figure 9A) and the SCTC (Figure 9B). The temperature profile in the PBTC maintains a narrow "S" shape, with the thermocline region occupying less than $4 \mathrm{~m}$ of the tank height. This excellent stratification results in the high efficiency of $92.37 \%$ for the PBTC. The temperature profile in the SCTC exhibits a much less sharp "S" shape, with the thermocline region expanding to fill more than $6 \mathrm{~m}$ of the tank height. This decreased level of stratification leads to the decreased system efficiency of the SCTC relative to the PBTC of $84 \%$.
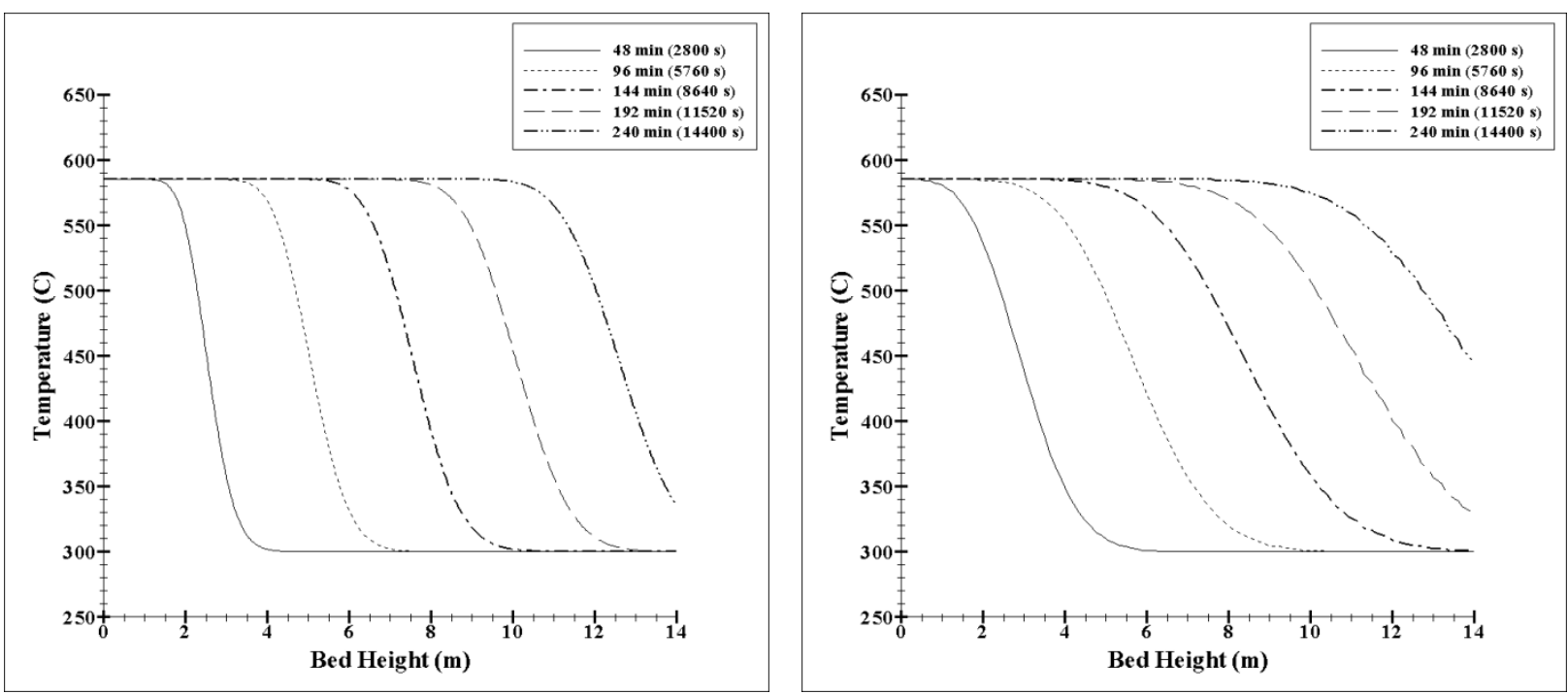

Figure 9: Solid media temperature Profiles during the charging process for PBTC (Left, A) and SCTC (Right, B)

\section{Installed Cost of Utility PBTC and SCTC}

Pacheco et al. [8] present what appears to be the first cost analysis of a liquid-based PBTC. Considering an indirect configuration, temperature differential of $84^{\circ} \mathrm{C}$, and solar salt and quartzite media, a cost of $\$ 13,900,000$ is calculated for a $688 \mathrm{MWh}$ system, corresponding to a capacity cost of $\$ 20 / \mathrm{kWh}$. However, the cost analysis considers few system components and is for a very low temperature range. EPRI [5] reports a much more thorough and detailed cost analysis procedure. Cost analysis of PBTC and two-tank TES systems, considering both direct and indirect configurations, and ranging in capacity from $100 \mathrm{MWh}$ to $3,500 \mathrm{MWh}$ are considered. Utilizing this blue print, cost analysis is performed on the PBTC and SCTC TES systems. 
For this comparison, a 2,165 MWh TES system is considered. This system operates between $290^{\circ} \mathrm{C}$ and $565^{\circ} \mathrm{C}$ and supplies a $100 \mathrm{MW}$ central receiver CSP with up to 8 hours of backup energy. A fixed tank height of $20 \mathrm{~m}$ is considered for both systems; the fluid fraction of both systems is $33 \%$ and the top and base $10 \%$ of each tank is left free from solid media. Based upon this information, tank diameters of $27 \mathrm{~m}$ and $29 \mathrm{~m}$ are calculated for the PBTC and SCTC systems. It should be noted that the $20 \mathrm{~m}$ tank height considered is hypothetical, as it is not known whether or not such a tank can practically be built. The majority of TES systems reported in [7] implement larger-volume, but shorter tanks having dimensions of $14 \mathrm{~m}$ height and $36 \mathrm{~m}$ diameter. However, for the purposes of this study, the proposed tank height of $20 \mathrm{~m}$ shall be considered. Utilizing the media costs reported in Table 5, the media cost for each system is computed and reported in Table 6.

Table 5: Unit and capacity costs of TES media

\begin{tabular}{|c|c|c|}
\hline Media & $\begin{array}{l}\text { Cost } \\
\left(\$ / \mathbf{m}^{3}\right)\end{array}$ & $\begin{array}{c}\text { Capacity Cost } \\
(\$ / k W h)\end{array}$ \\
\hline Solar Salt & $\$ 2,118.3$ & $\$ 10.83$ \\
\hline Limestone & $\$ 36.9$ & $\$ 0.16$ \\
\hline Concrete & $\$ 228.5$ & $\$ 1.46$ \\
\hline
\end{tabular}

Table 6: TES media costs for PBTC and SCTC.

\begin{tabular}{|l|rr|}
\hline \multicolumn{1}{|c|}{ Media } & \multicolumn{2}{|c|}{ Thermocline Configuration } \\
& PBTC & \multicolumn{1}{c|}{ SCTC } \\
\hline Salt Inventory $\left(\mathrm{m}^{3}\right)$ & 4,304 & 5,250 \\
Salt Cost & $\$ 9,117,181$ & $\$ 11,122,098$ \\
Solid Media Inventory $\left(\mathrm{m}^{3}\right)$ & 7,651 & 10,500 \\
Solid Media Cost & $\$ 282,789$ & $\$ 2,415,114$. \\
Media Subtotal $\mathbf{( \$ )}$ & $\mathbf{\$ 9 , 3 9 9 , 9 7 0}$ & $\mathbf{\$ 1 3 , 5 3 7 , 2 1 2}$ \\
\hline
\end{tabular}

For thermocline-type TES systems in the range of 1,000 MWh to 2,500 MWh, the cost of many system components increases linearly [5]. Having attained the media cost for each system, linear interpolation between 2,000 $\mathrm{MWh}$ and 2,500 $\mathrm{MWH}$ systems is used to find the cost of each cost component found in Table 7. It can be seen that most of the components (located above subcomponent subtotal) are the same; the primary cost differences are the added cost of the SCTC's tank and media. The three contributors located directly below the component subtotal row are expressed as percentages of the component subtotal. The remaining costs, construction 
and management, are constants. Dividing the installed cost of each system by the energy storage capacity expressed in kWh yields the storage capacity cost of each system.

Table 7: Cost analysis of PBTC and SCTC TES Systems

\begin{tabular}{|l|rr|}
\hline \multicolumn{1}{|c|}{ Cost Contributor } & \multicolumn{2}{|c|}{ Thermocline Configuration } \\
& PBTC & \multicolumn{1}{c|}{ SCTC } \\
\hline Energy Storage Media & $\$ 9,399,970$ & $\$ 13,537,212$ \\
Storage Tank & $\$ 13,780,582$ & $\$ 17,795,201$ \\
Foundation & $\$ 4,772,480$ & $\$ 4,772,480$ \\
Platform and Steel & $\$ 1,449,300$ & $\$ 1,449,300$ \\
Insulation & $\$ 1,062,800$ & $\$ 1,062,800$ \\
Filler Preheating Equip. & $\$ 1,833,770$ & $\$ 1,833,770$ \\
Surge Tanks & $\$ 366,471$ & $\$ 366,471$ \\
Pumps and PCE & $\$ 6,673,660$ & $\$ 6,673,660$ \\
Salt Melting System & $\$ 2,764,530$ & $\$ 2,764,530$ \\
Piping and Valves & $\$ 2,177,830$ & $\$ 2,177,830$ \\
Electrical & $\$ 550,742$ & $\$ 550,742$ \\
Instrumentation/Controls & $\$ 322,118$ & $\$ 322,118$ \\
Energy Cost Melting Salt & $\$ 347,076$ & $\$ 347,076$ \\
Component Subtotal (CS) & $\mathbf{\$ 4 5 , 5 0 1 , 3 2 9}$ & $\mathbf{\$ 5 3 , 6 5 3 , 1 9 1}$ \\
Contingency (15\% CS) & $\$ 6,825,199$ & $\$ 8,047,978$ \\
Sales Tax (8.75\% CS) & $\$ 3,981,366$ & $\$ 4,694,654$ \\
Engineering (3\% CS) & $\$ 1,365,039$ & $\$ 1,609,595$ \\
Construction Costs & $\$ 5,847,630$ & $\$ 5,847,630$ \\
Construction Management & $\$ 1,500,000$ & $\$ 1,500,000$ \\
Installed Cost & $\mathbf{\$ 6 5 , 0 2 0 , 5 6 5}$ & $\mathbf{\$ 7 5 , 3 5 3 , 0 5 0}$ \\
Capacity Cost (\$/kWh) & $\mathbf{\$ 3 0}$ & $\mathbf{\$ 3 4}$ \\
\hline
\end{tabular}

From Table 7, it can be seen that the PBTC configuration is more than $12 \%$ less costly than the SCTC configuration. Comparing the computed thermocline capacity costs with the costs of other energy storage techniques (Table 1), it can be seen that both thermocline configurations offer energy storage at substantially reduced price. However, it must be noted that countermeasures against thermal ratcheting of the PBTC are not considered in this cost analysis.

A significant assumption that is made in this analysis is that the fabrication and construction costs of the PBTC and SCTC systems are the same, when in reality they likely would not be. For the SCTC, it is not feasible to cast and install concrete plates having dimensions of $2.2 \mathrm{~cm} \times 20 \mathrm{~m}$ x $29 \mathrm{~m}$. These large plates would instead be composed of many smaller plates installed within a framework. The concrete considered herein has compressive strength in excess of $138 \mathrm{MPa}(20 \mathrm{ksi})$, therefore, the resultant peak stress under self-weight of $0.44 \mathrm{MPa}$ is not a concern (even at high temperatures where there is some strength loss). Therefore, constructability of the specified system is deemed possible. Unfortunately, it is not possible to consider the additional construction costs of the SCTC (versus the PBTC) at this 
time. However, for the purpose of comparison, the currently-utilized approach is deemed reasonable.

\section{Discussion}

Based upon numeric modelling of PBTC and SCTC systems, it can be seen that the PBTC is about $8.5 \%$ more efficient than the SCTC $(92.37 \%$ vs. $84 \%)$. Furthermore, from Table 6 , it can be seen that the capacity cost of the PBTC is more than $12 \%$ less than that of the SCTC. This study indicates that the PBTC configuration is superior to the SCTC TES system both in terms of cost and performance. However, the SCTC configuration bears no concerns of thermal ratcheting, which is a significant concern for the PBTC system.

Strain gauge data from Solar One's tank indicates that hoop stress of $190 \mathrm{MPa}$, less than half of the yield strength of steel (400 MPa) was developed when the system was operated at a temperature differential of $84^{\circ} \mathrm{C}$. However, knowing that thermal strain is directly proportional to temperature, it is logical to assume that the severity of thermal ratcheting will increase with the temperature differential of the system. At the present, central-receiver CSP facilities systems such as Gemasolar already employ temperature differentials of up to $275^{\circ} \mathrm{C}$. These temperature differentials will only increase, as the Rankine power cycle is replaced by the more efficient Brayton cycle. Note that other aspects of the system design, such as geometry of the storage tank may also lead to enhancement of the thermal ratcheting effect. As the aspect ratio of the tank deviates from unity, thermal ratcheting will certainly be enhanced. However, the point made in this discussion is that give a particular storage system tank, increasing the operating temperature differential will accelerate thermal ratcheting of the tank.

Three countermeasures against thermal ratcheting have been discussed. Flueckiger et al. [13] proposes a perforated liner be placed between the steel tank wall and the aggregate bed, allowing the aggregate to expand without damaging the wall. However, unless an elastic material that is chemically compatible with molten salts and capable of resisting the repeated thermal cycles is proposed, this concept is not deemed viable at this time. Zanganeh et al. [15] propose a novel tank configuration; the tank is shaped as an inverted frustum, with the sloped walls encouraging the aggregate bed to expand upward. The confining tank walls are layers of concrete and the structure is buried so that the ground supports the walls. However, concrete is a permeable material, and salt has been found to permeate even very dense concretes [22]. To construct such a large-sized novel tank from, steel would require much engineering and 
construction work; these would likely lead to significant cost increase, rendering this concept not viable for liquid-based thermocline systems. The final countermeasure, proposed by Brown et al. [16] and this work, avoids the issue of thermal ratcheting altogether by replacing the packed aggregate bed with structured concrete plates. Though efficiency suffers somewhat due to conduction within the plates, a system configuration is proposed that is capable of providing energy storage at $38 \%$ of the cost of the current industry standard configuration and at $68 \%$ of the newer two-tank direct configuration with no concerns of thermal ratcheting and destruction of the system.

\section{Conclusions}

Based upon numeric modelling, a PBTC is $8.37 \%$ more efficient than a SCTC $(92.37 \%$ vs. 84\%). Cost analysis of utility-scale 2,165 MWh PBTC and SCTC TES systems indicates that a PBTC is $12.5 \%$ less costly than a SCTC ( $\$ 30 / \mathrm{kWh}$ vs. $\$ 34 / \mathrm{kWh}$ ). However, for the high temperature differential considered, $275^{\circ} \mathrm{C}$, thermal ratcheting of the tank's walls by the aggregate bed is a significant concern. Novel tank liners and configurations have been proposed as countermeasures for thermal ratcheting, but these options are not currently viable. A structured concrete thermocline bears no concerns of thermal ratcheting and offers energy storage at significant cost reduction to the most economic TES system configuration, two-tank direct, in use at this time. Therefore, it is concluded that a SCTC is currently the most viable TES option; however, efforts should still be made to develop countermeasures for thermal ratcheting in PBTC systems, as they offer higher efficiency and simplicity of construction.

\section{Acknowledgments}

This research work was supported by a grant from the U.S. Department of Energy (Grant \# DE-FG36-08GO18147) through the University of Arkansas. The opinions expressed in the paper do not reflect those of the research sponsor.

The authors would also like to thank the reviewers and editors for their thorough critique of this work which resulted in significant improvement of the reporting of the work.

\section{References}


1. Goswami, D.Y.; Kreith, F.; Kreider, J.F. Principles of Solar Engineering. (2 ${ }^{\text {nd }}$ ed.). 2000, New York: Taylor \& Francis.

2. Feldman, D.; Barbose, G.; Margolis, R.; Wiser, R.; Darghouth, N.; \& Goodrich, A. (2012). Photovoltaic (PV) Pricing Trends: Historical, Recent, and Near-Term Projections (No. DOE/GO-102012-3839). National Renewable Energy Laboratory (NREL), Golden, CO.. http://www.nrel.gov/docs/fy13osti/56776.pdf.

3. Denholm, P.; \& Mehos, M. (2011). Enabling greater penetration of solar power via the use of CSP with thermal energy storage. Contract, 303, 275-3000. www.nrel.gov/csp/pdfs/52978.pdf.

4. Schoenung, S. "Energy storage systems cost update." SAND2011-2730 (2011). http://prod.sandia.gov/techlib/accesscontrol.cgi/2011/112730.pdf.

5. EPRI (2010). "Solar Thermocline Storage Systems: A Preliminary Design Study". http://et.epri.com/publicdocuments.html-1019581.

6. Medrano, M.; Gil, A.; Martorell, I.; Potau, X.; \& Cabeza, L.F. State of the Art on HighTemperature Thermal Energy Storage for Power Generation. Part 2-Case Studies. Renewable and Sustainable Energy Reviews. 2010, 14, 56-72.

7. NREL, 2014. "Concentrating Solar Projects". http://www.nrel.gov/csp/solarpaces/operational.cfm.

8. Pacheco, J.E; Showalter, S.K.; \& Kolb, W.J. Development of a Molten-Salt Thermocline Thermal Storage System for Parabolic Trough Plants. J.Sol.Energy.Eng. 2002, 124, 153159.

9. Van Lew, J.T: Li, P; Chan, C.L; Karaki, W; \& Stephens, J. Analysis of Heat Storage and Delivery of a Thermocline Tank Having Solid Filler Material. J.Sol.Energy.Eng. 2011, 133, 021003.

10. Van Lew, J.T.; Li, P., Chan, C.L.; Karaki, W.; \& Stephens, J., 2009. "Transient Heat Delivery and Storage Process in a Thermocline Heat Storage System". Pro. ASME IMECE2009: Florida, USA.

11. Brosseau, D.; Kelton, J.; Ray, D.; Edgar, M.; Chisman, K.,; \& Emms, B. Testing of Thermocline Filler Materials and Molten-Salt Heat Transfer Fluids for Thermal Energy Storage Systems in Parabolic Trough Power Plants. J.Sol.Energy.Eng. 2005, 127, 109116.

12. Herrmann, U.; \& Kearney, D.W. Survey of Thermal Energy Storage for Parabolic Trough Power Plants. J.Sol.Energy.Eng. 2002, 124, 145-151. 
13. Flueckiger, S.; Yang, Z.; and Garimella, S.V. An Integrated thermal and Mechanical Investigation of Molten-Salt Thermocline Energy Storage. Applied Energy. 2011, 88, 2098-2105.

14. Flueckiger, S.M.; Yang, Z.; \& Garimella, S.V. Thermomechanical Simulation of the Solar One Thermocline Storage Tank. J.Sol.Energy.Eng. 2012, 134, 041014: 1-6.

15. Zanganeh, G.; Pedretti, A.; Zavattoni, S.; Barbato, M.; \& Steinfeld, A. Packed-bed thermal storage for concentrated solar power-Pilot-scale demonstration and industrialscale design. J. Solar Energy. 2012, 86, 3084-3098.

16. Brown, B.; Strasser, M.; \& Selvam, R.P. Proceedings of ASES. Development of a Structured Thermocline Thermal Energy Storage System. 2012, Paper No. 0074. Denver, CO.

17. Skinner, J., 2011. "Testing of Ultra-High Performance Concrete as a Thermal Energy Storage Medium at High Temperatures". Master's Thesis, University of Arkansas.

18. Laing, D.; Steinmann, W-D.; Tamme, R.; \& Richter, C. Solid Media Thermal Storage for Parabolic Trough Power Plants. J. Solar Energy. 2006, 80, 1283-1289.

19. Laing, D.; Steinmann, W-D.; FiB, M.; Tamme, R.; Brand, T.; \& Bahl, C. Solid Media Thermal Storage Development and Analysis of Modular Storage Operation Concepts for Parabolic Trough Power Plants. J.Sol.Energy.Eng. 2008, 130, 011006.

20. Laing, D.; Lehmann, D.; Fiss, M.; \& Bahl, C. Test Results of Concrete Thermal Energy Storage for parabolic Trough Power Plants. J.Sol.Energy.Eng. 2009, 131, 041007.

21. Laing, D.; Bauer, T.; Lehmann, D.; \& Bahl, C. "Development of a Thermal Energy Storage System for Parabolic Trough Power Plants with Direct Steam Generation". J.Sol.Energy Eng. 2010, 132, 021011-1-8.

22. Skinner, J.E.; Strasser, M.N.; Brown, B.M.; \& Selvam, R.P. Testing of HighPerformance Concrete as a Thermal Energy Storage Medium at High Temperatures. J.Sol.Energy.Eng. 2014, 136, 021004.

23. John, E.; Hale, M.; \& Selvam, P. Concrete as a thermal energy storage medium for thermocline solar energy storage systems. J. Solar Energy. 2013, 96, 194-204.

24. Strasser, M.N., 2012. "Performance and Cost Analysis of a Structured Concrete Thermocline Thermal Energy storage System”. Master's Thesis, University of Arkansas.

25. Schuman, T. Heat Transfer: A Liquid Flowing Through a Porous Prism. Franklin Institute. 1929, 405-41. 
26. Kuravi, S.; Trahan, J.; Goswami, D.Y.; Rahman, M.M.; \& Stefanakos, E.K., 2013. "Thermal Energy Storage Technologies and Systems for Concentrating Solar Power Plants." Progress in Energy and Combustion Science, Article in Press: http://www.sciencedirect.com/science/article/pii/S0360128513000026.

27. Mawire, A.; \& McPherson, M. Experimental and Simulated Temperature Distribution of an Oil-Pebble Bed Thermal Energy Storage System with a Variable Heat Source. Applied Thermal Engineering. 2009, 29, 1086-1095.

28. McMahan, A.C., 2006. "Design \& Optimization of Organic Rankine Cycle SolarThermal Powerplants". Master's Thesis, University of Wisconsin-Madison.

29. Yang, X.; Yang, X.; Ding, J.; Shao, Y.; Qin, F.G.F.; \& Jiang, R. Criteria for performance improvement of a Molten Salt Thermocline Storage System. Applied Thermal Engineering. 2012, 48, 24-31.

30. Valmiki, M.M.; Karaki, W.; Li, P.; Van Lew, J.; Chan, C.; \& Stephens, J. Experimental Investigation of Thermal Storage Processes in a Thermocline Tank. J.Sol.Energy.Eng. 2012, 134, 041003.

31. Xu, C., Wang, Z., He, Y., Li, X., \& Bai, F., 2012. "Sensitivity analysis of the numerical study on the thermal performance of a packed-bed molten salt thermocline thermal storage system". Applied Energy, 92, 65-75.

32. Schmidt, F.; Willmott, A. Thermal Energy Storage and Regeneration. 1981, Washington: McGraw-Hill.

33. Çengel, Y. Heat and Mass Transfer: A Practical Approach. (3rd ed.). 2007, New York: McGraw-Hil.

34. Xu, B.; Li, P-W.; Chan, C.L. "Extending the validity of lumped capacitance method for large Biot number in thermal storage application". J. Solar Energy. 2012, 86, 1709-1724. 